\title{
Phenolic profiles of Portuguese olive fruits (Olea europaea L.): Influences of cultivar and geographical origin
}

\author{
Ana F. Vinha ${ }^{\text {a }}$, Federico Ferreres ${ }^{\text {b }}$, Branca M. Silva ${ }^{a}$, Patrícia Valentão ${ }^{a}$,

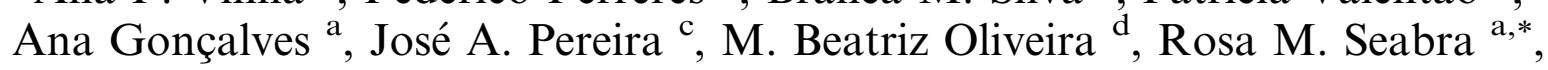 \\ Paula B. Andrade ${ }^{\text {a }}$ \\ ${ }^{a}$ REQUIMTE, Serviço de Farmacognosia, Faculdade de Farmácia, Universidade do Porto, R. Aníbal Cunha, 164, 4050-047 Porto, Portugal

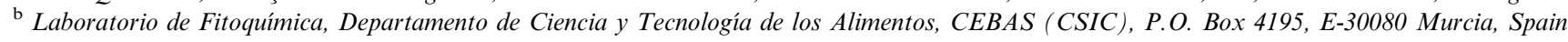

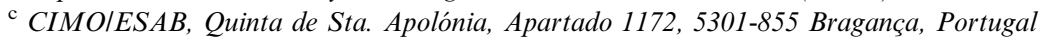 \\ ${ }^{\text {d }}$ REQUIMTE, Serviço de Bromatologia, Faculdade de Farmácia, Universidade do Porto, R. Aníbal Cunha, 164, 4050-047 Porto, Portugal
}

Received 4 April 2003; received in revised form 8 March 2004; accepted 8 March 2004

\begin{abstract}
The phenolic compounds present in 29 samples of olive fruits were analysed by reversed-phase HPLC/DAD and/or HPLC-DAD/ ESI-MS/MS. All samples were collected during the normal picking period for olive oil production, in north and central Portugal, and were obtained from 18 different olive cultivars.

Two different extraction methods were necessary for the complete quantification of phenolic compounds, a methanolic extraction and an extraction which included a solid-phase extraction (SPE) cleaning step.

The analyses showed that all samples presented a similar profile, which included at least six identified phenolic compounds: hydroxytyrosol, luteolin 7-O-glucoside, oleuropein, rutin, apigenin 7-O-glucoside and luteolin. Several samples also contained 5-Ocaffeoylquinic acid, verbascoside, quercetin 3-O-rhamnoside, cyanidin 3-O-glucoside and cyanidin 3-O-rutinoside.

In all samples, hydroxytyrosol and oleuropein were the major compounds identified while, in general, rutin and luteolin 7-Oglucoside were the two main flavonoids.

The influences of maturation index, nature of the cultivar and geographical origin are discussed. (C) 2004 Elsevier Ltd. All rights reserved.
\end{abstract}

Keywords: Olea europaea L.; Olive fruit; Portuguese olive cultivars; Anthocyanins; Phenolics; HPLC-DAD; HPLC-DAD/MS/MS - ESI

\section{Introduction}

Phenolic compounds are secondary plant metabolites, with a great structural diversity and a wide phylogenetic distribution (Harborne, 1989).

The most important classes of phenolic compounds in olive fruit include phenolic acids, phenolic alcohols, flavonoids and secoiridoids (Macheix, Fleuriet, \& Billot, 1990; Ryan \& Robards, 1998; Soler-Rivas, Espín, \& Wichers, 2000). The phenolic alcohols of olives are 3,4-dihydroxyphenylethanol (hydroxytyrosol) and $p$-hydroxyphenylethanol (tyrosol) (Macheix et al., 1990;

\footnotetext{
${ }^{*}$ Corresponding author. Tel.: +351-222-078-934; fax: +351-222-003977.

E-mail address: rseabra@ff.up.pt (R.M. Seabra).
}

Mazza \& Miniati, 1993; Romero, Brenes, García, \& Garrido, 2002; Ryan \& Robards, 1998). The most frequently described flavonoids include luteolin 7-Oglucoside, rutin and apigenin 7-O-glucoside, and the anthocyanins, cyanidin 3-O-glucoside and cyanidin 3-Orutinoside (Amiot, Fleuriet, \& Macheix, 1986, 1989; Esti, Cinquanta, \& La Notte, 1998; Romani, Mulinacci, Pinelli, Vincieri, \& Cimato, 1999; Ryan \& Robards, 1998). In some cultivars, a delphinidin glycoside has also been described (Macheix et al., 1990). Oleuropein and ligustroside are the predominant secoiridoids of olive fruit pulp. Some oleuropein derivatives have also been described, namely demethyloleuropein, oleuropein aglycone and elenolic acid (Amiot et al., 1989; Esti et al., 1998; Romani et al., 1999; Soler-Rivas et al., 2000). Verbascoside is the main hydroxycinnamic acid 
derivative of olive fruit (Romani et al., 1999; Ryan \& Robards, 1998; Servili, Baldioli, Selvaggini, Macchioni, $\&$ Montedoro, 1999).

Phenolic compounds, in general, and secoiridoids in particular, influence the sensorial properties of olive fruits and virgin olive oils and are largely responsible for the modifications occurring during the processing of table olives (Brenes, Rejano, García, Sánchez, \& Garrida, 1995). In virgin olive oils, they are the main agents responsible for the resistance against autoxidation and photoxidation (Botía et al., 2001; Papadopoulos \& Boskou, 1999; Romani et al., 1999).

Quantitative and even qualitative changes in the phenolic composition occur during ripening and considerable differences can be observed according to the stage of development of the fruit (Amiot et al., 1986, 1989; Esti et al., 1998; Romani et al., 1999).

For many years people have known that olives from some cultivars are more suited to the production of table olives, while others are used for oil production and that the oils obtained from different cultivars have different characteristics. These differences relate to differences in chemical composition of the olive cultivars.

As far as we know, no reports on the nature and/or concentrations of phenolic compounds in Portuguese olive cultivars exist. Therefore, in the present work, the phenolic compounds of twenty nine samples collected from eighteen Portuguese olive fruit cultivars, considered the most common in Portugal, were identified and quantified. Correlations between phenolic profile, cultivar and geographical origin are discussed.

\section{Materials and methods}

\subsection{Samples}

Olive fruits (Tables 1-3) were collected from different locations in north (Macedo de Cavaleiros, Mirandela, Valpaços, Mogadouro and Figueira de Castelo Rodrigo) and central Portugal (Fundão and Castelo Branco), yielding a total of 29 samples from 18 different cultivars. In each region, the chosen cultivars were those predominating in the respective area. The samples were collected in the period which coincided with the time when olives are usually harvested for oil production.

Healthy olive fruit samples were collected at different times between November and December of 2000, which coincided with the harvesting time of each region. For each sample, about $500 \mathrm{~g}$ of these fruits were manually collected from around three olive trees (approximately $1.5 \mathrm{~m}$ high). The fruits were stored at $-20{ }^{\circ} \mathrm{C}$ and the cores were removed before lyophilisation. The lyophilisations were carried out using a Labconco 4.5 apparatus (Kansas City, USA). Each lyophilised sample was
Table 1

Olive samples characterization

\begin{tabular}{|c|c|c|c|}
\hline Cultivars & Geographic origin & M.I. ${ }^{\mathrm{a}}$ & Sample \\
\hline \multirow[t]{2}{*}{ Bical } & Macedo de Cavaleiros & 3.4 & A1 \\
\hline & Mogadouro & 2.5 & $\mathrm{~A} 2$ \\
\hline Bical de Castelo & Castelo Branco & 3.3 & $\mathrm{~B} 1$ \\
\hline Branco & Fundão & 2.5 & $\mathrm{~B} 2$ \\
\hline Borreira & Mogadouro & 3.3 & $\mathrm{C} 1$ \\
\hline \multirow[t]{2}{*}{ Borrenta } & Valpaços & 3.8 & D1 \\
\hline & Mirandela & 3.3 & $\mathrm{D} 2$ \\
\hline \multirow[t]{4}{*}{ Cobrançosa } & Valpaços & 4.0 & E1 \\
\hline & Mirandela & 3.9 & E2 \\
\hline & Fundão & 3.1 & E3 \\
\hline & Mogadouro & 2.4 & E4 \\
\hline Cordovesa & Macedo de Cavaleiros & 3.6 & $\mathrm{~F} 1$ \\
\hline Cordovil de Castelo & Fundão & 3.8 & G1 \\
\hline Branco & Castelo Branco & 3.3 & G2 \\
\hline Cornicabra & $\begin{array}{l}\text { Figueira de Castelo } \\
\text { Rodrigo }\end{array}$ & 4.2 & $\mathrm{H} 1$ \\
\hline \multirow[t]{2}{*}{ Galega } & Castelo Branco & 4.2 & I1 \\
\hline & Fundão & 4.1 & $\mathrm{I} 2$ \\
\hline Lentisca & Valpaços & 2.8 & $\mathrm{~J} 1$ \\
\hline \multirow[t]{2}{*}{ Madural } & Mirandela & 4.3 & K1 \\
\hline & Valpaços & 3.3 & $\mathrm{~K} 2$ \\
\hline Madural Fina & Mogadouro & 3.2 & $\mathrm{~L} 1$ \\
\hline Madural Negra & Mogadouro & 3.3 & M1 \\
\hline Negrinha do Freixo & $\begin{array}{l}\text { Figueira de Castelo } \\
\text { Rodrigo }\end{array}$ & 6.2 & N1 \\
\hline Picual & Mirandela & 6.5 & $\mathrm{O} 1$ \\
\hline Roupuda & Mogadouro & 1.5 & P1 \\
\hline Santulhana & Mogadouro & 2.7 & Q1 \\
\hline Verdeal & Macedo de Cavaleiros & 4.6 & $\mathrm{R} 1$ \\
\hline \multirow[t]{2}{*}{ Transmontana } & Mirandela & 4.1 & $\mathrm{R} 2$ \\
\hline & Valpaços & 2.2 & R3 \\
\hline
\end{tabular}

${ }^{\mathrm{a}}$ M.I. - maturation index.

powdered to pass a $910 \mu \mathrm{m}$ sieve, before the extraction of phenolics.

The maturation index (M.I.) was determined according to Hermoso et al. (1991) and varied between 0 and 7. Olive fruits, 100 for each sample, were randomly taken, classified into the categories below, and homogenized prior to storage. The categories were: 0 - olives with intense green or dark green epidermis; 1 - olives with yellow or yellowish green epidermis; 2 - olives with yellowish epidermis but with reddish spots or areas over less than half of the fruit; 3 - olives with reddish or light violet epidermis over more than half of the fruit; 4 olives with black epidermis and totally white pulp; 5 olives with black epidermis and less than $50 \%$ purple pulp; 6 - olives with black epidermis and violet (more than $50 \%$ ) or purple pulp; 7 - olives with black epidermis and totally dark pulp.

With $a$ to $h$ being the number of fruits in each category, the M.I. is

$$
\begin{aligned}
\text { M.I. }= & (a \times 0+b \times 1+c \times 2+d \times 3+e \times 4+f \times 5 \\
& +g \times 6+h \times 7) / 100 .
\end{aligned}
$$


Table 2

Non-flavonoidic composition of olive fruit samples ( $\mathrm{mg} / \mathrm{kg}(\text { dry weight) })^{\mathrm{a}}$

\begin{tabular}{|c|c|c|c|c|c|}
\hline \multirow[t]{2}{*}{ Sample } & \multicolumn{4}{|c|}{ Phenolic composition } & \multirow[t]{2}{*}{$\sum$} \\
\hline & $\begin{array}{l}\text { Hydroxytyrosol } \\
\text { RT }=8.89 \mathrm{~min} \\
\text { Comp } 1\end{array}$ & $\begin{array}{l}\text { Oleuropein } \\
\mathrm{RT}=41.01 \mathrm{~min} \\
\text { Comp } 7\end{array}$ & $\begin{array}{l}\text { 5-Caffeoylquinic acid } \\
\text { RT }=16.91 \mathrm{~min} \\
\text { Comp } 2\end{array}$ & $\begin{array}{l}\text { Verbascoside } 3 \\
\mathrm{RT}=32.21 \mathrm{~min} \\
\text { Comp } 3\end{array}$ & \\
\hline A1 & $13,105(302)$ & 7434 (159) & $2.6(0.10)$ & $1.9(0.0061)$ & 20,543 \\
\hline A2 & $9342(86.4)$ & $1015(1.51)$ & $2.0(0.25)$ & $17.3(0.28)$ & 10,376 \\
\hline $\mathrm{B} 1$ & 4239 (128) & 4025 (107) & $\operatorname{tr}$ & $69.5(3.33)$ & 8333 \\
\hline $\mathrm{B} 2$ & $3828(22.2)$ & $5856(59.9)$ & $1.7(0.06)$ & $2.9(0.04)$ & 9689 \\
\hline $\mathrm{C} 1$ & $12,940(180.1)$ & $1834(303)$ & $4.6(0.30)$ & $144(9.21)$ & 14,922 \\
\hline D1 & $6244(58.13)$ & $1842.8(39.22)$ & $\operatorname{tr}$ & $191.9(2.27)$ & 8279 \\
\hline D2 & $2781(6.30)$ & $388(6.08)$ & $1.6(0.04)$ & $27.9(0.46)$ & 3198 \\
\hline E1 & $2735(12.2)$ & $1493(31.5)$ & $5.7(0.12)$ & $164.4(5.60)$ & 4400 \\
\hline $\mathrm{E} 2$ & $5408.6(169.72)$ & $2335(123)$ & $9.3(0.39)$ & $76.6(2.60)$ & 7823 \\
\hline E3 & $15,200(435.6)$ & $966(5.83)$ & $3.2(0.18)$ & $100(1.67)$ & 16,269 \\
\hline $\mathrm{E} 4$ & $8150(127)$ & $1276(7.53)$ & $2.6(0.71)$ & $0.7(0.017)$ & 9429 \\
\hline $\mathrm{F} 1$ & $3741(14.5)$ & $3681(31.5)$ & $8.1(0.10)$ & $32.8(0.70)$ & 7463 \\
\hline G1 & $10,901(584)$ & $4901(122)$ & $\operatorname{tr}$ & $89.3(0.29)$ & 15,892 \\
\hline G2 & 397 (27.9) & $3090(224)$ & $3.4(0.09)$ & $24.7(0.05)$ & 7088 \\
\hline $\mathrm{H} 1$ & $5519(227)$ & $13703(227)$ & $4.6(0.13)$ & $84.7(0.55)$ & 19,311 \\
\hline I1 & $2312(58.6)$ & $479(6.97)$ & $3.5(0.16)$ & $32.5(0.36)$ & 2827 \\
\hline $\mathrm{I} 2$ & 3498 (132) & $757(1.40)$ & $\operatorname{tr}$ & $111(2.85)$ & 4366 \\
\hline $\mathrm{J} 1$ & $27,673(55.1)$ & $21,681(466)$ & $3.9(0.12)$ & $9.2(0.05)$ & 49,367 \\
\hline K1 & $4843(179.8)$ & $1860(2.84)$ & $9.1(0.27)$ & $209(1.30)$ & 6921 \\
\hline $\mathrm{K} 2$ & $7288(93)$ & $4398(60.1)$ & $0.6(0.03)$ & $164(2.74)$ & 11,851 \\
\hline $\mathrm{L} 1$ & $71,354(39.5)$ & $2113(10.2)$ & $4.7(0.22)$ & $69.5(3.43)$ & 73,541 \\
\hline M1 & $2163(108)$ & $930(2.10)$ & $2.4(0.54)$ & $2.7(0.07)$ & 3097 \\
\hline N1 & $2821(166)$ & 9943 (46.2) & $\operatorname{tr}$ & $106(1.70)$ & 12,870 \\
\hline $\mathrm{O} 1$ & $8100(289)$ & $10324(58.9)$ & $2.1(0.46)$ & $25.3(0.37)$ & 18,452 \\
\hline $\mathrm{P} 1$ & 9347 (169) & $4365(105)$ & $12.5(0.29)$ & $114(0.45)$ & 13,839 \\
\hline Q1 & $10,626(5.98)$ & $1580(13.2)$ & $2.4(0.03)$ & $28.8(0.039)$ & 12,237 \\
\hline $\mathrm{R} 1$ & $15,763(260)$ & $13643(90.3)$ & $2.3(0.043)$ & $174(1.58)$ & 29,583 \\
\hline $\mathrm{R} 2$ & $5451(42.1)$ & 509 (30.9) & $1.9(0.06)$ & $\operatorname{tr}$ & 5962 \\
\hline R3 & $1477(8.11)$ & $2799(8.15)$ & $1.0(0.12)$ & $0.9(0.06)$ & 4278 \\
\hline
\end{tabular}

${ }^{\mathrm{a}}$ Values are expressed as means (standard derivation) of three assays for each sample. tr, traces; $\sum$, sum of the determined compounds; RT retention time.

\subsection{Standards}

The standards used were from Sigma (St. Louis, MO, USA) or Extrasynthèse (Genay, France) and cyanidin 3$O$-glucoside and cyanidin 3-O-rutinoside were from Polyphenols (Sandnes, Norway). Methanol, formic and hydrochloric acids and $n$-hexane were obtained from Merck (Darmstadt, Germany). The water was treated in a Milli-Q water purification system (Millipore, Bedford, MA, USA) before use.

\subsection{Solid-phase extraction columns}

The ISOLUTE C18 non-end-capped (NEC) solidphase extraction (SPE) columns (50 $\mu$ m particle size, 60 A porosity; $10 \mathrm{~g}$ sorbent mass $/ 70 \mathrm{ml}$ reservoir volume) were purchased from International Sorbent Technology Ltd. (Mid Glamorgan, UK).

\subsection{Extraction of phenolic compounds}

The extraction was achieved as previously reported (Vinha et al., 2002): each sample (ca. $1.5 \mathrm{~g}$ ) was thor- oughly mixed with methanol until complete extraction of these compounds (negative reaction to $\mathrm{NaOH} 20 \%$ ). The methanolic extract was filtered, evaporated to dryness under reduced pressure $\left(40{ }^{\circ} \mathrm{C}\right)$ and redissolved in methanol $(4 \mathrm{ml})$ of which $20 \mu \mathrm{l}$ were injected for HPLC analysis.

\subsection{Purification of phenolic extract by SPE column}

About $1.5 \mathrm{~g}$ of each sample were subjected to extraction as previously described. The methanolic extract obtained was taken to dryness under reduced pressure $\left(40{ }^{\circ} \mathrm{C}\right)$, and redissolved in $50 \mathrm{ml}$ of acidified water $(\mathrm{pH} 2$ with $\mathrm{HCl}$ ) to avoid the ionisation of the phenolic compounds. The aqueous solution was then passed through an ISOLUTE C18 (NEC) column, previously conditioned with $60 \mathrm{ml}$ of methanol and $140 \mathrm{ml}$ of acidified water ( $\mathrm{pH} 2$ with $\mathrm{HCl}$ ). The loaded cartridge was washed with $60 \mathrm{ml}$ of $n$-hexane to eliminate the lipid fraction (Pirisi, Cabras, Cao, Migliorini, \& Muggelli, 2000) and the retained phenolic compounds were then eluted with methanol $(60 \mathrm{ml})$. The methanolic extract was concentrated to dryness under reduced pressure $\left(40{ }^{\circ} \mathrm{C}\right)$ 
Table 3

Flavonoidic composition of olive fruit samples (mg/kg (dry weight) $)^{\mathrm{a}}$

\begin{tabular}{|c|c|c|c|c|c|c|c|c|}
\hline \multirow[t]{2}{*}{ Sample } & \multicolumn{7}{|c|}{ Phenolic composition } & \multirow[t]{2}{*}{$\sum$} \\
\hline & $\begin{array}{l}\text { Cy-3-glucoside } \\
\mathrm{RT}=33.37 \\
\min \\
\text { Comp } 4\end{array}$ & $\begin{array}{l}\text { Cy-3-rutinoside } \\
\mathrm{RT}=37.02 \\
\min \\
\text { Comp } 5\end{array}$ & $\begin{array}{l}\text { Lut 7-gluc } \\
\text { RT }=40.28 \\
\min \\
\text { Comp } 6\end{array}$ & $\begin{array}{l}\text { Rutin } \\
\text { RT }=43.61 \\
\text { min } \\
\text { Comp } 8\end{array}$ & $\begin{array}{l}\text { Api 7-gluc } \\
\text { RT }=45.33 \\
\text { min } \\
\text { Comp } 9\end{array}$ & $\begin{array}{l}\text { Quer 3-rham } \\
\text { RT }=46.78 \\
\text { min } \\
\text { Comp } 10\end{array}$ & $\begin{array}{l}\text { Luteolin } \\
\mathrm{RT}=62.23 \\
\min \\
\text { Comp } 11\end{array}$ & \\
\hline A1 & $13.2(0.05)$ & $96.9(1.36)$ & $152(14.14)$ & $278(19.91)$ & $11.5(2.02)$ & $17.0(0.57)$ & $8.6(0.55)$ & 576 \\
\hline $\mathrm{A} 2$ & nd & nd & $257(6.59)$ & $320(26.5)$ & $66.2(4.80)$ & $44.4(0.49)$ & $86.5(3.60)$ & 775 \\
\hline B1 & $156(3.51)$ & $332(10.91)$ & $77.1(1.87)$ & $235(7.50)$ & $25.7(0.61)$ & $16.1(0.88)$ & $32.6(3.20)$ & 876 \\
\hline $\mathrm{B} 2$ & nd & nd & $419.9(4.12)$ & $387.1(3.92)$ & $28.1(0.19)$ & $20.5(0.33)$ & $3.4(0.79)$ & 859 \\
\hline $\mathrm{C} 1$ & $633(2.51)$ & $78.3(1.46)$ & $886(64.91)$ & $1139(22.92)$ & $247(27.3)$ & $119(12.5)$ & $7.8(0.57)$ & 2540 \\
\hline D1 & $\operatorname{tr}$ & $\operatorname{tr}$ & $135(1.25)$ & $688(8.90)$ & $192(1.77)$ & $122.8(1.63)$ & $14.7(0.41)$ & 1152 \\
\hline $\mathrm{D} 2$ & $\operatorname{tr}$ & $\operatorname{tr}$ & $152(3.17)$ & $223(6.43)$ & $56.6(1.62)$ & $100.9(4.45)$ & $41.5(2.40)$ & 574 \\
\hline E1 & $141(2.50)$ & $206(4.90)$ & $38.7(4.17)$ & $740(23.3)$ & $417(11.7)$ & $162(4.25)$ & $9.4(1.09)$ & 1714 \\
\hline $\mathrm{E} 2$ & $78.1(1.39)$ & $159(2.15)$ & $255(20.9)$ & $1095.0(10.7)$ & $39.4(1.07)$ & $55.6(0.80)$ & $15.9(0.15)$ & 1697 \\
\hline E3 & nd & nd & $343(0.62)$ & $586(11.9)$ & $118(1.25)$ & $46.3(1.51)$ & $131(4.01)$ & 1225 \\
\hline $\mathrm{E} 4$ & nd & nd & $78.1(6.56)$ & $175(19.9)$ & $39.7(0.87)$ & $31.9(1.40)$ & $57.9(4.53)$ & 382 \\
\hline $\mathrm{F} 1$ & $\operatorname{tr}$ & $\operatorname{tr}$ & $718(37.7)$ & 603 (16.5) & $73.5(4.18)$ & $54.0(1.58)$ & $82.6(6.45)$ & 1531 \\
\hline G1 & $180(3.13)$ & $200(1.46)$ & $492(3.77)$ & $628.2(7.31)$ & $106(0.08)$ & $65.0(0.71)$ & $39.4(2.53)$ & 1711 \\
\hline $\mathrm{G} 2$ & nd & nd & $355(1.66)$ & $713(30.3)$ & $173(1.89)$ & $37.6(0.06)$ & $101(0.16)$ & 1380 \\
\hline $\mathrm{H} 1$ & $60.9(0.62)$ & $221(4.01)$ & $846(5.98)$ & $1060(13.2)$ & $154(0.96)$ & $95.2(8.70)$ & $19.1(1.23)$ & 2456 \\
\hline I1 & nd & nd & $638(11.14)$ & 497 (19.49) & $58.9(1.55)$ & $189(5.04)$ & $154(6.83)$ & 1537 \\
\hline $\mathrm{I} 2$ & $\operatorname{tr}$ & $\operatorname{tr}$ & $126(2.99)$ & $268(5.76)$ & $46.2(5.86)$ & $9.6(0.37)$ & $22.0(0.49)$ & 472 \\
\hline $\mathrm{J} 1$ & nd & nd & $327(3.28)$ & $1061(43.55)$ & $59.8(1.14)$ & $56.9(0.26)$ & $122(3.88)$ & 1627 \\
\hline $\mathrm{K} 1$ & $\operatorname{tr}$ & $573(16.06)$ & $690(8.21)$ & $915(83.05)$ & $180(9.81)$ & $54.6(0.55)$ & $251(0.61)$ & 2664 \\
\hline $\mathrm{K} 2$ & $\operatorname{tr}$ & $30.1(0.13)$ & $648(1.19)$ & $747(23.26)$ & $112(16.2)$ & $17.4(7.53)$ & $94.5(3.01)$ & 1649 \\
\hline $\mathrm{L} 1$ & nd & nd & $666(54.99)$ & $686(40.39)$ & $80.1(5.11)$ & $125(6.82)$ & $116(5.35)$ & 1674 \\
\hline M1 & nd & nd & $275(2.77)$ & $422(2.43)$ & $155(2.78)$ & $69.7(2.11)$ & $94.0(5.07)$ & 1015 \\
\hline N1 & $1060(21.4)$ & $1405.1(23.66)$ & $510(7.52)$ & $683(2.08)$ & $179(14.3)$ & $64.6(3.70)$ & $14.8(0.17)$ & 3916 \\
\hline $\mathrm{O} 1$ & $522.51(8.06)$ & 768 (12.9) & $455(7.62)$ & $645(28.8)$ & $37.0(1.30)$ & $43.1(20.43)$ & $3.3(0.09)$ & 2474 \\
\hline $\mathrm{P} 1$ & nd & nd & $526(2.42)$ & $1070(3.21)$ & $90.8(1.16)$ & $193(1.05)$ & $56.7(1.82)$ & 1936 \\
\hline Q1 & nd & nd & $257(0.75)$ & $343(4.55)$ & $54.1(8.05)$ & $64.9(0.81)$ & $440(2.60)$ & 1158 \\
\hline $\mathrm{R} 1$ & $100(0.85)$ & $207(0.78)$ & $352(3.79)$ & $655(6.78)$ & $59.2(1.12)$ & $\operatorname{tr}$ & $106(1.26)$ & 1481 \\
\hline $\mathrm{R} 2$ & nd & nd & $63.2(0.11)$ & $204(3.42)$ & $34.5(0.91)$ & $25.9(0.72)$ & $18.5(0.91)$ & 346 \\
\hline R3 & nd & nd & $11.9(0.60)$ & $185(10.3)$ & $102(0.85)$ & $138(9.97)$ & $6.1(0.65)$ & 442 \\
\hline
\end{tabular}

${ }^{a}$ Values are expressed as means (standard derivation) of three assays for each sample. tr, traces; nd, not detected; $\sum$, sum of the determined phenolics; Cy-3-glucoside, cyanidin 3-O-glucoside; Cy-3-rutinoside, cyanidin 3-O-rutinoside; Lut 7-gluc, luteolin 7-O-glucoside; Api 7-gluc, apigenin 7-O-glucoside; Quer 3-rham, quercetin 3-O-rhamnoside; RT - retention time.

and redissolved in methanol $(4 \mathrm{ml})$. The injection volume for HPLC analysis was $20 \mu 1$.

\subsection{HPLC-DAD system for qualitative and quantitative analysis of phenolic compounds}

Chromatographic separation was carried out as reported previously (Vinha et al., 2002), with an analytical HPLC unit (Gilson), using a Spherisorb ODS2 column $(250 \times 4.6 \mathrm{~mm}, \mathrm{RP}-18,5 \mu \mathrm{m}$ particle size, Merck, Darmstadt, Germany) with the solvent system waterformic acid (19:1) (A) and methanol (B), starting with $5 \%$ methanol and installing a gradient to obtain $15 \% \mathrm{~B}$ at $3 \mathrm{~min}, 25 \% \mathrm{~B}$ at $13 \mathrm{~min}, 30 \% \mathrm{~B}$ at $25 \mathrm{~min}, 35 \% \mathrm{~B}$ at 35 min, $40 \% \mathrm{~B}$ at $39 \mathrm{~min}, 45 \% \mathrm{~B}$ at $42 \mathrm{~min}, 45 \% \mathrm{~B}$ at 45 $\mathrm{min}, 47 \%$ B at $50 \mathrm{~min}, 48 \% \mathrm{~B}$ at $60 \mathrm{~min}, 50 \% \mathrm{~B}$ at $64 \mathrm{~min}$ and $100 \% \mathrm{~B}$ at $66 \mathrm{~min}$. The flow rate was $0.9 \mathrm{ml} / \mathrm{min}$, and the injection volume was $20 \mu \mathrm{l}$. Detection was achieved with a diode array detector, and chromatograms were recorded at 280, 320 and $500 \mathrm{~nm}$.
Spectral data from all peaks were accumulated in the range $200-600 \mathrm{~nm}$. The data were processed on a Unipoint ${ }^{\circledR}$ system software (Gilson Medical Electronics, Villiers le Bel, France).

Phenolic compounds quantification was achieved by the absorbance recorded in the chromatograms relative to external standards. Verbascoside was quantified as 5$O$-caffeoylquinic acid, cyanidin 3-O-rutinoside as cyanidin 3-O-glucoside and hydroxytyrosol as tyrosol. The remaining compounds were quantified as themselves. Hydroxytyrosol and oleuropein were quantified at 280 $\mathrm{nm}$, the anthocyanins at $500 \mathrm{~nm}$ and all the other compounds at $320 \mathrm{~nm}$.

\subsection{HPLC-DAD/MS system for anthocyanins identifica- tion}

Chromatographic separation was carried out on a LiChroCART column $(250 \times 4 \mathrm{~mm}, \mathrm{RP}-18,5 \mu \mathrm{m}$ particle size, Merck, Darmstadt, Germany), using the solvent 
system water-formic acid (19:1) (A) and methanol (B), starting with $5 \%$ methanol and installing a gradient to obtain at $3 \mathrm{~min}-15 \% \mathrm{~B}, 13 \mathrm{~min}-25 \% \mathrm{~B}, 25 \mathrm{~min}-30 \%$ B, $35 \min -35 \%$ B, $39 \min -40 \%$ B, $42 \min -45 \%$ B, 45 $\min -45 \%$ B, $50 \min -47 \%$ B, $60 \mathrm{~min}-48 \%$ B, $64 \mathrm{~min}-$ $50 \% \mathrm{~B}$ and $66 \mathrm{~min}-100 \% \mathrm{~B}$. The flow rate was $0.9 \mathrm{ml} /$ min, and the injection volume was $80 \mu \mathrm{l}$. Spectral data from all peaks were accumulated in the $240-600 \mathrm{~nm}$ range and chromatograms were recorded at $500 \mathrm{~nm}$.

The HPLC system was equipped with a DAD and mass detector in series (Agilent 1100 Series LC/MSD Trap). It consisted of an Agilent G1312A HPLC binary pump, an Agilent G1313A autosampler, an Agilent G1322A degasser and an Agilent G1315B photo-diode array detector controlled by Agilent software v. A.08.03 (Agilent Technologies, Waldbronn, Germany). The mass detector was an Agilent G2445A ion-trap mass spectrometer (Agilent Technologies, Waldbronn, Germany) equipped with an electrospray ionisation (ESI) system and controlled by Agilent Software v. 4.0.25. Nitrogen was used as nebulizing gas at a pressure of $65 \mathrm{psi}$ and the flow was adjusted to $11 \mathrm{l} / \mathrm{min}$. The heated capillary and voltage were maintained at $350^{\circ} \mathrm{C}$ and $4 \mathrm{kV}$, respectively. The full scan mass spectra of the phenolic compounds were measured from $\mathrm{m} / z 100$ up to $\mathrm{m} / z$ 2000. Collisioninduced fragmentation experiments were performed in the ion trap, using helium as the collision gas, while the collision energy was set at $100 \%$. Mass spectrometry data were acquired in the positive ionisation mode.

\section{Results and discussion}

\subsection{Identification of the compounds}

The peaks on the chromatogram at $500 \mathrm{~nm}$ (Fig. 1, peaks 4 and 5) showed identical spectra, with two maxima at 280 and $516-518 \mathrm{~nm}$, which suggested the presence of anthocyanins or anthocyanin derivatives. Upon HPLC-MS analysis, peak 4 showed a pseudomolecular ion $[\mathrm{M}+\mathrm{H}]^{+}$at $m / z 449$ and the $\mathrm{MS}^{2}$ event yielded a fragment ion at $m / z$ at 287 , typical mass in the positive mode of the cyanidin aglycone, corresponding to the loss of glucose $(\mathrm{m} / \mathrm{z} 162)$. An authentic standard of cyanidin 3-O-glucoside was injected and the retention time, UV and MS spectra matched those of peak 4. Therefore, peak 4 was identified as cyanidin 3-Oglucoside.

Peak 5 showed a pseudomolecular ion $[\mathrm{M}+\mathrm{H}]^{+}$at $m / z 595$ and the $\mathrm{MS}^{2}$ event yielded a fragment ion at $m / z$ at 287 , typical mass in the positive mode of the cyanidin aglycone, corresponding to the loss of rutinoside $(m / z$ 308). An authentic standard of cyanidin 3-Orutinoside was injected and the retention time, UV and MS spectra matched those of peak 5 . Therefore, peak 5 was identified as cyanidin 3-O-rutinoside.
The non-coloured phenolic compounds were identified by comparison of their retention times and UV-Vis spectra in the 200-600 $\mathrm{nm}$ range with those obtained from standards. Verbascoside was identified by comparison with the compound already described by us from Lippia citriodora (Valentão, Andrade, Areias, Ferreres, \& Seabra, 1999).

The majority of olive samples presented the same chemical profile, composed of 11 identified phenolic compounds: hydroxytyrosol, 5- $O$-caffeoylquinic acid, verbascoside, luteolin 7-O-glucoside, oleuropein, rutin, apigenin 7-O-glucoside, quercetin 3-O-rhamnoside, luteolin, cyanidin 3-O-glucoside and cyanidin 3-O-rutinoside (Fig. 1). Some samples revealed the presence of two unidentified compound (compounds a and b), with retention time 35.20 and $50.41 \mathrm{~min}$, respectively. These compounds presented as UV spectrum closely related to that of oleuropein, leading us to presume that they could be an oleuropein derivative, as was observed in some Australian cultivars (Ryan et al., 2002).

\subsection{Quantitative results}

As a general rule, when the cleaning step was used the amount of each phenolic compound extracted was higher. However, when this cleaning step was used, oleuropein presented a lower recovery rate (Vinha et al., 2002). To check what happened to oleuropein, a given amount of this standard was subjected to the same treatment; when the eluate was analysed we found that oleuropein was degradated and a peak with a higher retention time $(47.04 \mathrm{~min})$ and with the same spectra (probably oleuropein aglycone) was also found (data not shown). Therefore, the quantification of oleuropein was made in the extract without pre-treatment on a SPE column (Table 2).

Among the identified compounds, hydroxytyrosol and oleuropein were the major phenolic compounds (Table 2). The analysis of Table 2 reveals considerable quantitative differences in oleuropein contents among the different cultivars: the amount of oleuropein ranged from $388 \mathrm{mg} / \mathrm{kg}$ (D2) to $21,681 \mathrm{mg} / \mathrm{kg}$ (J1), with a mean value of $4549 \mathrm{mg} / \mathrm{kg}$. In $48 \%$ of the analysed cultivars, the oleuropein content was above $3000 \mathrm{mg} / \mathrm{kg}$. These values are higher than those reported by Romani et al. (1999) and Esti et al. (1998) for Italian cultivars but lower than some values reported by Amiot et al. (1986) for French cultivars.

In general the values found for hydroxytyrosol can also be considered as high, when compared with published data. In fact, 27 of the 29 samples analysed showed levels ranging from $1477 \mathrm{mg} / \mathrm{kg}$ (R3) to 15,763 $\mathrm{mg} / \mathrm{kg}$ (R1) but two samples (J1 and L1) presented values even greater, amounting to 27,872 and 71,354 $\mathrm{mg} / \mathrm{kg}$, respectively, while most values found in the literature range from about $300 \mathrm{mg} / \mathrm{kg}$ (Esti et al., 1998) to 

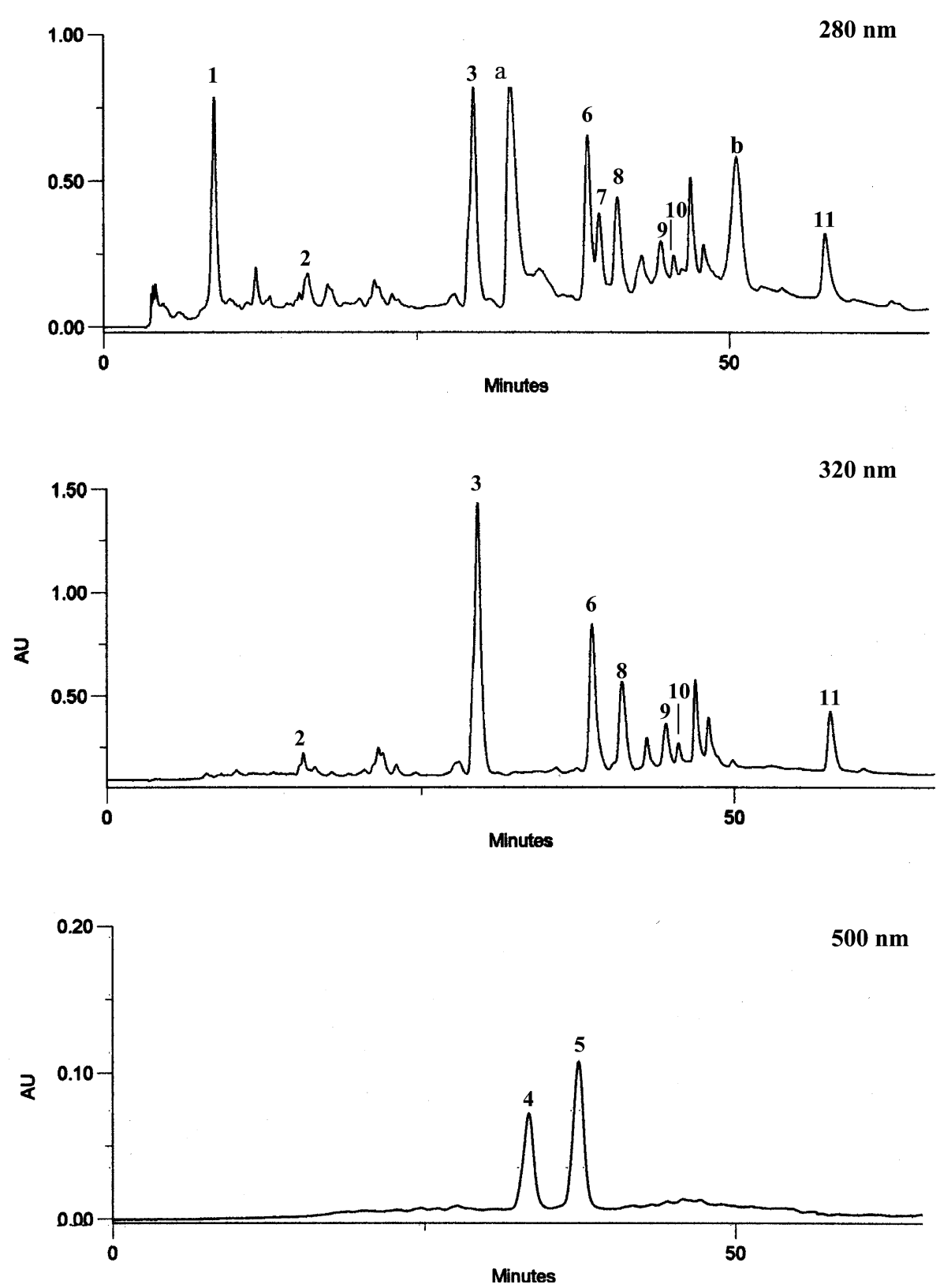

Fig. 1. HPLC phenolic profile of Picual sample. (1) hydroxytyrosol; (2) 5-O-caffeoylquinic acid; (3) verbascoside; (4) cyanidin 3-O-glucoside; (5) cyanidin 3-O-rutinoside; (6) luteolin 7-O-glucoside; (7) oleuropein; (8) rutin; (9) apigenin 7-O-glucoside; (10) quercetin 3-O-rhamnoside; (11) luteolin; (a and b) unidentified secoiridoid compounds.

$8000 \mathrm{mg} / \mathrm{kg}$ (Romani et al., 1999). In addition, hydroxytyrosol contents were generally higher than oleuropein concentrations which contrasts with the previous studies by Esti et al. (1998) and Servili et al. (1999). Although hydroxytyrosol is sometimes considered as a degradation product of oleuropein (which leads some authors to believe that during maturation oleuropein decreases as hydroxytyrosol increases), this observation could not be confirmed in this study: in fact, samples with higher M.I. did not show high values for the ratio hydroxytyrosol/oleuropein and no correlation was found between M.I. and hydroxytyrosol contents, even for the same cultivar.
Tyrosol is a phenolic alcohol, usually present in olives, although in lower amounts than hydroxytyrosol (Romani et al., 1999). However, in the analysed samples, it was only found in vestigial amounts (Lentisca, Borrenta and Santulhana cultivars) or even absent (data not shown).

Chlorogenic acid, first reported to occur in leaves of Olea europaea, was found for the first time in olives by Ryan et al. (2002) and is now confirmed and quantified in 23 of the 29 analysed samples, although in amounts below $12.5 \mathrm{mg} / \mathrm{kg}$.

The Portuguese studied cultivars showed very low amounts of verbascoside (below $0.02 \%$ ) when compared 
with those from other studied cultivars, namely the Italian ones studied by Romani et al. (1999) and the French ones studied by Amiot et al. (1986) who found values around $0.5 \%$. This observation corroborates the correlation already noticed by Amiot et al. (1986) and later reasonably confirmed by Esti et al. (1998), that the cultivars with the highest oleuropein content were those with the least verbascoside.

Five non-coloured flavonoids were identified and quantified. In 25, out of the 29 analysed samples, luteolin 7-O-glucoside and rutin were the predominant flavonoids and, in general, rutin was present in higher amounts than the luteolin derivative. This seems to be a fact common to other olive cultivars, since these two compounds are always reported to occur in olive fruits, even when other compounds are not present (Esti et al., 1998; Servili et al., 1999). Free luteolin is always present in low amounts (usually below $100 \mathrm{mg} / \mathrm{kg}$ ) except in the case of sample Q1 $(434 \mathrm{mg} / \mathrm{kg}$, M.I. 2.72) and in sample K1 $(251 \mathrm{mg} / \mathrm{kg}$, M.I. 4.25). Although it is generally accepted that free flavonoids appear at the end of the maturation stage as a consequence of hydrolytic processes, no correlation was found between maturation index and the levels of free luteolin. Therefore, we may hypothesise that at least the high levels found in Santulhana (sample Q1) may be a characteristic of this cultivar.

Besides cyanidin 3-O-glucoside and cyanidin 3-O-rutinoside, no other anthocyanins were detected. In all cases, cyanidin 3-O-rutinoside was present in higher amounts than cyanidin 3-O-glucoside, a fact that has already been verified in cultivars analysed by Romani et al. (1999). As expected, the samples with higher levels of anthocyanins were those with higher maturation indices, namely sample N1 (M.I. 6.2, with $2465 \mathrm{mg} / \mathrm{kg}$ ) and sample O1 (M.I. 6.5, with $1291 \mathrm{mg} / \mathrm{kg}$ ). However, a strict correlation between M.I. and the amount of anthocyanins was not found. For instance sample B1, with a M.I. of 3.3, presented higher amounts of anthocyanins than many other samples with higher M.I., leading to the assumption that factors other than ripeness influence the anthocyanin content. The high levels of anthocyanins in Negrinha do Freixo (sample N1) and Picual (sample O1) can be explained by the fact that the fruits of these cultivars are usually consumed as naturally black table olives, which means that they are collected when almost black (the other cultivars are usually used for oil production and are collected before they reach complete maturation).

\subsection{Factors influencing the phenolic profile}

Several factors are known to affect the quantitative phenolic profiles of olive fruits. Among these factors, the degree of ripeness, the geographical origin and the nature of the cultivar are certainly those that have a pronounced influence on the composition. Some studies are already published concerning the influence of these factors on some French (Amiot et al., 1986) Spanish (Botía et al., 2001) and Italian (Esti et al., 1998; Romani et al., 1999) cultivars.

The samples that were the object of the study presented herein have different geographical origins and different maturation indices and were collected from different cultivars. Although the strict influence of one factor can only be evaluated when all other factors remain constant, some clear conclusions can be drawn from the results herein obtained. For example, samples B1 and B2, two samples from the same cultivar but with different M.I. and geographical origins, have similar phenolic profiles for the major compounds, pointing to a strong influence of the cultivar. However, when comparing other samples, we can observe a stronger influence of the geographical origin. For instance, on comparing samples A2, E4, and Q1, three samples from the same geographical origin and with similar M.I. (2.5, 2.4 and 2.7, respectively), but collected from different cultivars, there are very similar phenolic profiles, denoting a strong influence of geographical origin. The same can be observed for the samples N1 and H1, that exhibit similar profiles, even with very different M.I.s. The influence of the geographical origin can also be observed when comparing samples from the same cultivar and with very similar M.I.s as shown for the sample pairs R1/R2 and G1/G2 and E1/E2.

Although the geographical origin seems to play an important role in the pattern of phenolic profiles, some of the Portuguese cultivars now analysed seem to have characteristic phenolic profiles: Santulhana (sample Q1) for its high amount of free luteolin, Lentisca (sample J1) for its high level of hydroxytyrosol plus oleuropein and Madural Fina (sample L1) for its very high hydroxytyrosol/oleuropein ratio (33.8:1). Samples B2, H1, N1, R3 and $\mathrm{O} 1$ are the only ones where oleuropein clearly surpasses the level of hydroxytyrosol; it is not possible to prove whether this is a characteristic of the cultivar or alternatively related to geographical origin; this can only be confirmed from more analysis in samples collected during future years.

If future analysis confirms the results now obtained, we can conclude that at least two Portuguese cultivars may produce excellent olive oils in terms of oxidative resistance, given their very high levels of hydroxytyrosol and oleuropein, two compounds that are considered to give strong protection against autoxidation and thermoxidation of olive oil (Papadopoulos \& Boskou, 1999).

\section{Acknowledgements}

Branca M. Silva is grateful to Fundação para a Ciência e a Tecnologia for a Grant (PRAXIS XXI/BD/ 21339/99). 


\section{References}

Amiot, M. J., Fleuriet, A., \& Macheix, J. J. (1986). Importance and evolution of phenolic compounds in olive during growth and maturation. Journal of Agricultural and Food Chemistry, 34, 823-826.

Amiot, M. J., Fleuriet, A., \& Macheix, J. J. (1989). Accumulation of oleuropein derivatives during olive maturation. Phytochemistry, 28, 67-69.

Botía, J. M., Ortuño, A., Benavente-García, O., Báidez, A. G., Frías, J., Marcos, D., \& Del Río, J. A. (2001). Modulation of the biosynthesis of some phenolic compounds in Olea europaea L. fruits: Their influence on olive oil quality. Journal of Agricultural and Food Chemistry, 49, 355-358.

Brenes, M., Rejano, L., García, P., Sánchez, H., \& Garrida, A. (1995). Biochemical changes in phenolic compounds during spanish-style green olive processing. Journal of Agricultural and Food Chemistry, 43, 2702-2706.

Esti, M., Cinquanta, L., \& La Notte, E. (1998). Phenolic compounds in different olive varieties. Journal of Agricultural and Food Chemistry, $46,32-35$.

Harborne, J. B. (1989). General procedures and measurement of total phenolics. In P. M. Dey \& J. B. Harborne (Eds.), Methods in plant phenolics (pp. 2-9). London: Academic Press.

Hermoso, M., Uceda, M., García, A., Morales, B., Frias, M. L., \& Fernández, A. (1991). Elaboración de aceite de calidad. Consejeria de Agricultura y Pesca, Serie Apuntes, 5/92., Sevilla.

Macheix, J. J., Fleuriet, A., \& Billot, J. (1990). Fruit phenolics (pp. 1126). Boca Raton, FL: CRC Press.

Mazza, G., \& Miniati, E. (1993). Anthocyanins in fruits, vegetables and grains (pp. 64-67). Boca Raton, FL: CRC Press.

Papadopoulos, G., \& Boskou, D. (1999). Antioxidant effect of natural phenols on olive oil. JAOCS, 68, 669-671.

Pirisi, F. M., Cabras, P., Cao, C. F., Migliorini, M., \& Muggelli, M. (2000). Phenolic compounds in virgin olive oil. 2. Reappraisal of the extraction, hplc separation, and quantification procedures. Journal of Agricultural and Food Chemistry, 48, 1191-1196.

Romani, A., Mulinacci, N., Pinelli, P., Vincieri, F. F., \& Cimato, A. (1999). Polyphenolic content in five Tuscany cultivars of Olea europaea L. Journal of Agricultural and Food Chemistry, 47, 964 967.

Romero, C., Brenes, M., García, P., \& Garrido, A. (2002). Hydroxytyrosol 4- $\beta$-D-glucoside, an important phenolic compound in olive fruits and derived products. Journal of Agricultural and Food Chemistry, 50, 3835-3839.

Ryan, D., Antolovich, M., Herlt, T., Prenzler, P. D., Lavee, S., \& Robards, K. (2002). Identification of phenolic compounds in tissues of the novel olive cultivar Hardy's Mammoth. Journal of Agricultural and Food Chemistry, 50, 6716-6724.

Ryan, D., \& Robards, K. (1998). Phenolic compounds in olives. Analyst, 123, 31R-44R.

Servili, M., Baldioli, M., Selvaggini, R., Macchioni, A., \& Montedoro, G. (1999). Phenolic compounds of olive fruits: One- and twodimensional nuclear magnetic resonance characterization of nuzhenide and its distribution in the constitutive parts of fruit. Journal of Agricultural and Food Chemistry, 47, 12-18.

Soler-Rivas, C., Espín, J. C., \& Wichers, H. J. (2000). Oleuropein and related compounds. Journal of the Science of Food and Agriculture, 80, 1013-1023.

Valentão, P., Andrade, P. B., Areias, F., Ferreres, F., \& Seabra, R. M. (1999). Analysis of vervain flavanoids by HPLC/Diode array detector method. Its application to quality control. Journal of Agricultural and Food Chemistry, 47, 4579-4582.

Vinha, A. F., Silva, B. M., Andrade, P. B., Seabra, R. M., Pereira, J. A., \& Oliveira, M. B. (2002). Development and evaluation of an HPLC/DAD method for the analysis of phenolic compounds from olive fruits. Journal of Liquid Chromatography \& Related Technology, 25, 151-160. 